\title{
Sexual Dysfunction in Postmenopausal Women with Breast Cancer on Adjuvant Aromatase Inhibitor Therapy
}

\author{
Daniel María Lubián López ${ }^{a, b} \quad$ Carmen Aisha Butrón Hinojo ${ }^{c}$ \\ Manuel Sánchez-Prieto ${ }^{d}$ Nicolás Mendoza ${ }^{e}$ Rafael Sánchez-Borrego ${ }^{f}$

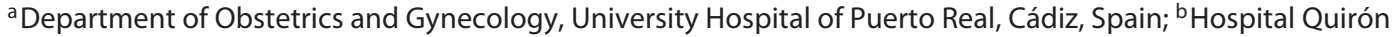 \\ Salud Campo de Gibraltar, University of Cádiz, Cádiz, Spain; ' Department of Obstetrics and Gynecology, \\ Hospital of Algeciras, Cádiz, Spain; ${ }^{\mathrm{d}}$ Department of Obstetrics and Gynecology, Institut Universitari Dexeus, \\ Barcelona, Spain; ' Department of Obstetrics and Gynecology, University of Granada, Granada, Spain; \\ fDepartment of Obstetrics and Gynecology, DIATROS, Clínica de Atención a la Mujer, Barcelona, Spain
}

\section{Keywords}

Aromatase inhibitors · Breast cancer survivors .

Sexual dysfunction · Female Sexual Function Index ·

EORTC QLQ-BR23 · State-Trait Anxiety Inventory questionnaire

\begin{abstract}
Introduction: The aim of this study was to investigate whether postmenopausal women with breast cancer (BC) on adjuvant aromatase inhibitor (AI) therapy have a higher prevalence of female sexual dysfunction (FSD). Second, the aim was to determine the quality of life (QoL) and level of anxiety depending on whether or not they are Al users. Methods: A prospective cross-sectional study involving 168 patients was performed. Three questionnaires were carried out: sexual functioning was evaluated with the Female Sexual Function Index (FSFI), while the EORTC QLQ-BR23 measures to study QoL in patients with BC and the State-Trait Anxiety Inventory (STAI) questionnaire (trait and status) were used to assess anxiety status in patients under treatment with Als or not. Results: $47.6 \%(80 / 168)$ of the postmenopausal BC survivors were not sexually active (mean time after surgery: 48.6 months) despite a relatively low mean age (56.43 years). Postmenopausal Al-treated women had significantly worse sexual function as measured by the FSFI ( $23.40 \pm 5.26$ vs. $30.16 \pm 2.24 ; p=0.000)$. There were significant differences
\end{abstract}

between both groups in all domains, except orgasm. The QoL score was $37.67 \pm 7.38$ in Al users versus $39.00 \pm 1.44$ among nonusers $(p=0.053)$. Patients under endocrine treatment also presented STAI scores significantly higher (25.83 \pm 4.99 vs. $19.00 \pm 7.12 ; p=0.000$ ). Trait anxiety was high in both groups, but this was not statistically significant. Conclusions: We observed a high prevalence of sexual inactivity among $\mathrm{BC}$ survivors regardless of $\mathrm{Al}$ use. Patients with $\mathrm{Al}$ use presented significantly higher prevalence of FSD, worse QoL, and greater anxiety.

(c) 2020 S. Karger AG, Basel

\section{Introduction}

In developed countries, $75 \%$ of breast cancer (BC) incidents occur in postmenopausal women, with $70 \%$ of these cancers being estrogen receptor positive (ER+) [1].

In women with $\mathrm{BC}-\mathrm{ER}+$, clinical practice guidelines recommend the use of third-generation aromatase inhibitors (AIs; anastrozole, letrozole, and exemestane) in early-stage postmenopausal women as adjuvant endocrine therapy because they have shown better results in terms of disease-free and overall survival than tamoxifen (TMX), especially in patients at higher risk of recurrence [2]. However, side effects of endocrine therapy in preand postmenopausal patients can include significant va- 
Table 1. Demographic and clinical variables

\begin{tabular}{|c|c|c|c|c|}
\hline Outcome & $\begin{array}{l}\text { All patients } \\
(n=168 ; 100 \%)\end{array}$ & $\begin{array}{l}\text { Patients with AIs } \\
(n=144 ; 85.71 \%)\end{array}$ & $\begin{array}{l}\text { Patients without AIs } \\
(n=24 ; 14.28 \%)\end{array}$ & $p$ value \\
\hline Age, years & $56.23 \pm 8.66$ & $56.84 \pm 9.27$ & $54.93 \pm 0.48$ & 0.08 \\
\hline Menarche, years & $12.24 \pm 1.62$ & $12.24 \pm 1.60$ & $12.25 \pm 1.75$ & 0.966 \\
\hline Pretreatment menopause & & & & 0.002 \\
\hline Yes & $131(77.98)$ & $107(61.31)$ & $24(100)$ & \\
\hline No & $37(22.02)$ & $37(22.02)$ & $0(0)$ & \\
\hline Childbirth & $2.33 \pm 0.93$ & $2.39 \pm 1.01$ & $2 \pm 0.00$ & 0.043 \\
\hline Breastfeeding & & & & 0.07 \\
\hline Yes & $130(77.38)$ & $114(79.16)$ & $16(66.66)$ & \\
\hline No & $38(22.61)$ & $30(20.83)$ & $8(33.33)$ & \\
\hline Duration of breastfeeding, months & $6.97 \pm 4.87$ & $7.34 \pm 4.92$ & $5.14 \pm 4.23$ & 0.029 \\
\hline Family history of cancer ${ }^{\circ}$ & & & & 0.000 \\
\hline \multicolumn{5}{|l|}{ Yes } \\
\hline Breast & $37(22.02)$ & $37(22.02)$ & $0(0)$ & \\
\hline Ovary & $20(11.90)$ & $20(11.90)$ & $0(0)$ & \\
\hline No & $111(66.07)$ & $87(51.78)$ & $24(14.28)$ & \\
\hline Age at diagnosis of cancer, years & $51.49 \pm 8.47$ & $52.28 \pm 9.20$ & $49.32 \pm 0.47$ & 0.092 \\
\hline Survival time from diagnosis, months & $48.01 \pm 33.43$ & $48.22 \pm 35.54$ & $37.32 \pm 13.42$ & 0.100 \\
\hline Use of vaginal lubricants ${ }^{\mathrm{a}}$ & $36(40.90)$ & $31(43.00)$ & $5(37.50)$ & 0.235 \\
\hline Use of vaginal moisturizers ${ }^{\mathrm{a}}$ & $13(14.70)$ & $11(15.20)$ & $2(12.50)$ & 0.174 \\
\hline
\end{tabular}

Data are shown as the means \pm SD or absolute numbers (\%). ${ }^{a}$ Only when sexually active.

somotor dysfunction, weight gain, and overall decreased health-related quality of life (QoL) [3].

Anxiety is the most prevalent psychosocial sequela after cancer diagnosis [4]. Anxiety includes trait and state anxiety. High anxiety predicted worse QoL and well-being concurrently and longitudinally [5], and QoL is a key aspect of cancer survivorship.

Female sexual dysfunction (FSD) is a highly complex phenomenon and a well-described consequence of comprehensive $\mathrm{BC}$ care $[6,7]$. The diagnosis of $\mathrm{BC}$ itself, aspects of personality, and previous personal and sexual relationships influence the sexual function of patients with BC [8]. The type of surgery and adjuvant treatment also influence the sexual response of these patients $[9,10]$. Thus far, sexual function in AI-treated BC patients has only been studied with generic endocrine or QoL questionnaires that include some items on sexuality, but not with specific sexual function questionnaires. The results obtained, with these limitations, indicate that AI-treated patients report a decrease in sexual interest compared to TMX-treated patients and that AI treatment has negative effects on overall FSD [11]. However, there is a lack of studies focusing on more specific aspects of FSD conducted with specific questionnaires to assess sexual function in AI-treated patients.

Therefore, this study aimed to investigate whether AItreated patients with postmenopausal $\mathrm{BC}$ have a higher prevalence of FSD than those who do not use it. Second, we aimed to determine the QoL and level of anxiety among postmenopausal women survivors with BC depending on their use of AIs.

\section{Materials and Methods}

\section{Inclusion Criteria}

A prospective cross-sectional study was conducted with 168 postmenopausal women treated for BC. Participants were selected according to the following criteria: postmenopausal (more than 1 year of amenorrhea with FSH levels $\geq 40 \mathrm{mIU} / \mathrm{mL}$ ), invasive BC included in our database, aged between 50 and 70 years, BC-ER+ in current treatment with adjuvant endocrine therapy with AIs (study group; at least 12 months) or without adjuvant treatment at that time (ER-, ex-users for more than 5 years, no current need for it; control group), claimed to understand the purpose of the study, and signed informed consent to participate. Patients with stage IV $\mathrm{BC}$, those with a history of psychiatric pathology, including anxiety or depressive syndrome, women with a previous to current diagnosis of FSD, and patients with any other conditions related to sexual response (pelvic floor dysfunction, heart disease, diabetes, arthritis, drug or alcohol abuse, or use of antihypertensive drugs) were excluded.

\section{Methods}

A detailed gynecological history was taken in all patients, paying special attention to the treatments received both in a neoadjuvant and adjuvant form as well as the tumor stage and type of surgery performed. The term "sexually active" was used only for heterosexual relationship with penetration. Homosexual relationship and masturbation were not included.

QoL was measured by the EORTC QLQ-BR23 questionnaire [12], which measures more specific aspects of BC. The questions in the questionnaire are based on several multi-item scales and refer to the previous week. Patients completed the EORTC QLQBR23 questionnaire, which had been validated for use in Spain [13].

Participants completed the Female Sexual Function Index (FSFI) questionnaire. This questionnaire assesses 6 dimensions of sexual functioning over the previous 4 weeks; a total FSFI score 
Table 2. Type of surgery

\begin{tabular}{lllll}
\hline & $\begin{array}{c}\text { All patients } \\
(n=168)\end{array}$ & $\begin{array}{c}\text { Patients with } \\
\text { AIs }(n=144)\end{array}$ & $\begin{array}{l}\text { Patients without } \\
\text { AIs }(n=24)\end{array}$ & $p$ value \\
\hline $\begin{array}{l}\text { Breast-conserving therapy + SLNB or ALND } \\
\text { Mastectomy + SLNB or ALND }\end{array}$ & $\begin{aligned} 144(85.7) \\
24(14.3)\end{aligned}$ & $\begin{aligned} 125(86.8) \\
19(13.2)\end{aligned}$ & $\begin{array}{c}20(83.3) \\
4(16.7)\end{array}$ & 0.442 \\
\hline
\end{tabular}

All data are shown as $n$ (\%). SLNB, sentinel lymph node biopsy; ALND, axillary lymph node dissection.

Table 3. Clinical stage of breast cancer

\begin{tabular}{lclll}
\hline & $\begin{array}{c}\text { All patients } \\
(n=168)\end{array}$ & $\begin{array}{l}\text { Patients with } \\
\text { AIs }(n=144)\end{array}$ & $\begin{array}{l}\text { Patients without } \\
\text { AIs }(n=24)\end{array}$ & $p$ value \\
\hline Stage I & $101(60.11)$ & $90(62.50)$ & $14(58.33)$ & \\
Stage II & $53(31.54)$ & $42(29.16)$ & $8(33.33)$ & 0.142 \\
Stage III & $14(8.33)$ & $12(8.33)$ & $2(8.33)$ & \\
\hline
\end{tabular}

All data are shown as $n(\%)$.
Table 4. Sexual activity of the women

\begin{tabular}{lrrrr}
\hline & \multicolumn{2}{c}{ Current sexual activity } & \multirow{2}{*}{ Total } & $p$ value \\
\cline { 2 - 3 } & \multicolumn{1}{c}{ no } & yes & & \\
\hline No AIs & $8(33.33)$ & $16(66.66)$ & $24(100)$ & \\
AIs & $72(50.00)$ & $72(50.00)$ & $144(100)$ & 0.124 \\
Total & $80(47.60)$ & $88(52.30)$ & $168(100)$ & \\
\hline
\end{tabular}

All data are shown as $n(\%)$.
$<26.5$ is suggestive of FSD [8]. FSFI has been validated for women with cancer [14]. The Spanish FSFI is a valid and reliable instrument for assessing and discriminating FSD among Spanish postmenopausal women [15].

Finally, trait and state anxiety were assessed by the State-Trait Anxiety Inventory (STAI) [16], a questionnaire aimed at assessing the level of anxiety of individuals. More specifically, the STAI measures individuals' predisposition to perceive diverse stimuli as threatening (i.e., trait anxiety). STAI includes 2 subscales, the Trait Anxiety Scale (STAI-T) and the State Anxiety Scale (STAI-S), which contain 20 items for trait and state anxiety. We used a short version of the STAI validated for a Spanish sample [17]. Anxiety was considered low ( $<30$ points), medium (30-44 points), or high ( $>44$ points)

The results were compared according to whether or not the patients were under treatment with AIs.

\section{Statistical Analysis}

The data were collected and analyzed with SPSS 23.0 for Windows (version 23.0, SPSS Inc., USA). Clinical and demographic variables of the patients (age, parity, age of menarche, time of disease survival) were compared in the 2 groups of women (with and without AIs). The prevalence of FSD and altered QoL among postmenopausal women with $\mathrm{BC}$ were analyzed according to AI use as well as trait anxiety and state anxiety in each of the groups.

Statistical analysis was performed by calculating frequencies and means and standard deviations. Pearson's $\chi^{2}$ or Fisher's exact test was used for frequency comparison and Student $t$ test for mean comparisons. Statistical significance was established at $p<0.05$.

\section{Results}

This study involved 168 women, 144 (85.7\%) of whom were undergoing AI treatment (cases), while 24 (14.3\%) were without such treatment (controls). Table 1 shows a series of clinical and demographic variables of the patients. It should be noted that there were no differences between the 2 groups in the percentage of use of vaginal lubricants for sexual intercourse or the rate of use of vaginal moisturizers.

No differences were found between the 2 groups of patients in relation to the type of surgery performed (Table 2 ), the clinical stage of the tumor (Table 3), or whether they were sexually active at the time of the survey (Table $4)$.

\section{Quality of Life: EORTC QLQ-BR23}

The data collected from this questionnaire are shown in Table 5. The score of patients with adjuvant AI treatment was $37.67 \pm 7.38$ compared to $39.00 \pm 1.44$ for those who did not receive treatment ( $p=0.053$ ); therefore, although this first group seemed to have a worse QoL, it could not be stated categorically, as the statistical significance was at the limit.

Compared to those without treatment, AI-treated patients presented significantly worse body image (5.67 \pm 3.27 vs. $9.00 \pm 2.50 ; p=0.000)$; worse sexual function among patients with sexual activity (72 vs. $16: 3.39 \pm 1.53$ vs. $4.00 \pm 0.1 ; p=0.000)$; less sexual enjoyment ( $2.11 \pm$ 1.05 vs. $3.00 \pm 0.83 ; p=0.000)$; more concern about the future ( $2.39 \pm 1.21$ vs. $1.67 \pm 0.48$; $p=0.005)$; more concern about hair loss ( $1.61 \pm 1.11$ vs. $1.00 \pm 0.00 ; p=0.008)$, and more affectation at the breast level $(6.67 \pm 3.61 \mathrm{vs}$. $5.33 \pm 1.27 ; p=0.001$ ) (Table 5). Although not significant, AI users also showed greater effects of systemic treatment $(13.67 \pm 4.695$ vs. $12.00 \pm 3.00 ; p=0.095)$ and more symptoms in the arm $(4.28 \pm 1.86$ vs. $4.00 \pm 0.83 ; p=0.235)$. 
Table 5. EORTC QLQ-BR23

\begin{tabular}{lcccc}
\hline & $\begin{array}{c}\text { All patients } \\
(n=168)\end{array}$ & $\begin{array}{c}\text { Patients with } \\
\text { AIs }(n=144)\end{array}$ & $\begin{array}{c}\text { Patients without } \\
\text { AIs }(n=24)\end{array}$ & $p$ value \\
\hline Total score & $38.48 \pm 6.9$ & $37.67 \pm 7.38$ & $39.00 \pm 1.44$ & 0.053 \\
Body image $_{\text {Sexual functioning }}^{\mathrm{a}}$ & $5.95 \pm 3.31$ & $5.67 \pm 3.27$ & $9.00 \pm 2.50$ & $\mathbf{0 . 0 0 0}$ \\
Sexual enjoyment $^{\mathrm{a}}$ & $3.55 \pm 1.41$ & $3.39 \pm 1.53$ & $4.00 \pm 0.00$ & $\mathbf{0 . 0 0 0}$ \\
Concern about the future $_{\text {Systemic treatment effects }}^{2.32 \pm 1.05}$ & $2.11 \pm 1.05$ & $3.00 \pm 0.83$ & $\mathbf{0 . 0 0 0}$ \\
Concern about hair loss $_{\text {Breast symptoms }}^{2.17 \pm 1.07}$ & $2.39 \pm 1.21$ & $1.67 \pm 0.48$ & $\mathbf{0 . 0 0 5}$ \\
Arm symptoms & $13.53 \pm 4.57$ & $13.67 \pm 4.69$ & $12.00 \pm 3.00$ & 0.095 \\
& $1.58 \pm 1.10$ & $1.61 \pm 1.11$ & $1.00 \pm 0.00$ & $\mathbf{0 . 0 0 8}$ \\
\hline
\end{tabular}

Data are shown as the means \pm SD or absolute numbers (\%). Bold values indicate statistical significance. a Analyzed only in patients with sexual activity (72 in AI group vs. 16 in non-AI group).

Table 6. STAI

\begin{tabular}{|c|c|c|c|c|}
\hline & $\begin{array}{l}\text { All patients } \\
(n=168)\end{array}$ & $\begin{array}{l}\text { Patients with } \\
\text { AIs }(n=144)\end{array}$ & $\begin{array}{l}\text { Patients without } \\
\text { AIs }(n=24)\end{array}$ & $\begin{array}{l}p \\
\text { value }\end{array}$ \\
\hline & 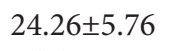 & 25.83 & 19.00 & 0.000 \\
\hline Trait anxiety & $26.61 \pm 7.20$ & $27.78 \pm 7.45$ & $29.33 \pm 12.49$ & 0.420 \\
\hline
\end{tabular}

Data are shown as means \pm SD. Bold values indicate statistical significance.

\section{Anxiety: STAI Questionnaire}

The values obtained in this questionnaire are shown in Table 6. Anxiety was assessed both at baseline (trait anxiety) and for state anxiety (which is produced at specific moments in the lives of patients as a result of a trigger, which, in this case, is BC).

Patients under AIs showed a significantly higher score in the area of state anxiety $(25.83 \pm 4.9$ vs. $19.00 \pm 7.12$; $p=0.000)$. There were no significant differences between the groups in terms of trait anxiety $(29.33 \pm 12.40$ in nonAI users vs. $27.78 \pm 7.45$ in AI users; $p=0.42$ ).

\section{Sexual Function: FSFI}

Of the 168 women participating in the study, only 88 were sexually active, of which $72(81.8 \%)$ were on adjuvant $\mathrm{AI}$ treatment, and 16 (18.2\%) were off this medication (Table 7). In general, AI-treated patients had significantly $(p=0.000)$ worse sexual function $(23.40 \pm 5.26)$ than those who did not take this treatment $(30.16 \pm 2.24)$. On average, AI users were within the range of what is considered sexual dysfunction $(<26.55)$, while nonusers were not.

Compared to those not taking AIs, we found that AItreated patients presented significantly lower sexual desire $(2.1 \pm 0.92$ vs. $4.17 \pm 0.83 ; p=0.000)$; significantly lower level of arousal $(3.90 \pm 1.23$ vs. $4.76 \pm 0.67 ; p=$
$0.015)$; significantly less lubrication at the time of sex $(4.20 \pm 0.61$ vs. $5.51 \pm 0.53 ; p=0.000)$, significantly more pain at penetration $(4.88 \pm 0.49$ vs. $3.60 \pm 1.23 ; p=0.001)$, and significantly less satisfaction in their sexual relationships (5.40 \pm 0.61 vs. $5.91 \pm 0.25 ; p=0.005)$.

Although not statistically significant $(p=0.094)$, women without AI treatment reached orgasm more easily than those taking AIs ( $4.75 \pm 1.27$ vs. $4.20 \pm 0.61)$.

\section{Discussion}

Even though most BC patients with partners "are sexually active in the year before surgery" [18], at 48.1 months of average follow-up, approximately half (47.6\%) of our patients were sexually inactive. A committee of multidisciplinary specialists reported in 2010 [19] that: "Cancer and its treatment has a significant impact on patient sexual function and satisfaction," which can be improved by "understanding pre-diagnostic sexual activity, undertaking less aggressive treatment, and using appropriate pharmacological and psychological treatment." All of this is important because, although we did not ask this question in our study, the high prevalence of sexual inactivity found among our patients could probably be reduced if they were invited to consult about its causes.

Regarding the assessment of QoL, we found a worse QoL in AI users than in nonusers. In the recent (2016) study carried out by de Morais et al. [20] with 77 patients, they showed, as we do, a low score in the domains of desire, frequency, and sexual satisfaction. However, unlike our study, the scores obtained in the body image section were higher in patients taking AIs. As for the significantly higher state anxiety score among AI patients than among those who were not treated with AIs, we point out that this has not been studied before; however, in the overall BC patients, our data coincide with a study carried 
Table 7. FSFI

\begin{tabular}{lcccc}
\hline Domains & $\begin{array}{l}\text { All sexually active } \\
\text { women }(n=88)\end{array}$ & $\begin{array}{l}\text { Sexually active } \\
\text { women on } \\
\text { AI treatment } \\
(n=16 ; 66.6 \%)\end{array}$ & $\begin{array}{l}\text { Sexually active } \\
\text { women without } \\
\text { AI treatment } \\
(n=72 ; 50.0 \%)\end{array}$ & $p$ value \\
\hline Desire & $3.83 \pm 1.21$ & $2.1 \pm 0.92$ & $4.17 \pm 0.83$ & $\mathbf{0 . 0 0 0}$ \\
Arousal & $4.67 \pm 0.86$ & $3.90 \pm 1.23$ & $4.76 \pm 0.67$ & $\mathbf{0 . 0 1 5}$ \\
Lubrication & $5.35 \pm 0.71$ & $4.20 \pm 0.61$ & $5.51 \pm 0.53$ & $\mathbf{0 . 0 0 0}$ \\
Orgasm & $4.70 \pm 1.24$ & $4.20 \pm 0.61$ & $7.75 \pm 1.27$ & 0.094 \\
Satisfaction & $5.78 \pm 0.42$ & $5.40 \pm 0.61$ & $5.91 \pm 0.25$ & $\mathbf{0 . 0 0 5}$ \\
Pain & $4.65 \pm 0.89$ & $4.88 \pm 0.49$ & $3.60 \pm 1.23$ & $\mathbf{0 . 0 0 1}$ \\
Total & $29.01 \pm 4.17$ & $23.40 \pm 5.26$ & $30.16 \pm 2.24$ & $\mathbf{0 . 0 0 0}$ \\
\hline
\end{tabular}

Data are shown as means \pm SD. Bold values indicate statistical significance. ${ }^{\text {a }}$ Genito-pelvic pain/penetration disorder.

out in China involving $60 \mathrm{BC}$ women [21]. Here, they determined this higher score as posttraumatic. This means that patients with $\mathrm{BC}$ have greater anxiety than the general population since they have suffered from the disease.

Regarding FSD, we have not found any studies that analyzed differences between the 2 populations (with or without AI treatment). Studies have observed a high prevalence of such sexual dysfunctions among users of hormone therapy (AIs or TMX) with respect to the general population without BC.

When comparing continuators (AI treatment adherence) and noncontinuators, Schover et al. [22] found lower scores among the continuators (although not statistically significant) for the total and all FSFI domains (desire, lubrication, orgasm, satisfaction), except for equal proportions of pain in both groups. Among all AI-treated patients, $93 \%$ were in the dysfunctional range in FSFI, and $75 \%$ were distressed by this problem [22]. As in our sample, only half of the women were sexually active, and almost $80 \%$ of that subgroup experienced new sexual problems after starting AIs. Half of the women with sexual problems sought help in trying to resolve them, including $24 \%$ of the patients who stopped having sex with their partners after treatment for BC. Thirty-nine percent of sexually active women with a new problem of vaginal dryness consulted a physician, and $18 \%$ sought help because of their low desire, which may indicate the severity of these problems.

Although vaginal dryness is debilitating and painful, having cancer, even without vaginal dryness, is also associated with problems in sexual intercourse, such as decreased sexual desire, arousal, orgasm, and intensity [23], which we confirmed in our study. In a recent study based on Internet evaluation, $63 \%$ of women reported that their diagnosis of ovarian cancer had negatively influenced their sex life, with a lack of interest in sex as their main complaint [24].
The 2013 study by Baumgart et al. [25], where the aim was to investigate sexual function in postmenopausal AItreated women with BC versus untreated or TMX controls, found similar results using a cross-sectional study to those found by us.

Recently, Gandhi et al. [26] conducted a survey of 278 $\mathrm{BC}$ survivors. No significant differences in the prevalence of sexual dysfunction were observed depending on the surgical modality, even when adjusted for adjuvant therapy. Chemotherapy or radiation was not associated with sexual dysfunction when adjusted for type of surgery. The prevalence of sexual dysfunction was 1.6 times higher for the AI group compared to the nonendocrine therapy group $(p=0.01)$, even when adjusted for other types of treatments. They concluded that the highest rates of sexual dysfunction are seen among BC survivors treated with AIs and that neither surgical modality, chemotherapy, nor radiation were associated with sexual dysfunction [26].

Regarding the treatment to improve such high rates of sexual dysfunction among AI users, although it was not the aim of our work, we comment that different clinical trials are being carried out on the efficacy of both hormonal and nonhormonal, local and systemic treatment, as well as sexual psychotherapies [27]. These discussions and management decisions can be complex but are of paramount importance to the QoL of cancer survivors with vulvovaginal atrophy $[28,29]$. However, earlier treatment of vulvovaginal atrophy symptoms, when symptoms are moderate rather than severe, may be associated with greater treatment benefits [30].

\section{Study Strengths and Limitations}

In addition to the possible methodological problems with research on sexual functioning and being aware that sexual problems associated with cancer treatment may be undervalued in patient interviews and surveys, a potential 
limitation of our study is that of an observational study and the possible response biases when dealing with an intimate subject, such as sexuality, and with more peculiar implications in older patients with a serious pathology who can "blame themselves" for their decrease in sexual activity due to that cause. However, despite being a population with a higher presumed prevalence of these FSDs, this should be homogeneous among all patients, and the finding of a higher prevalence among women under treatment with AIs, and not in nonusers, would support the role of the most marked hypoestrogenism in the genesis or maintenance of FSD.

Another limitation of the study is the low representativeness of the group without AIs (24 controls vs. 144 cases), since most BCs among postmenopausal women are hormone receptor positive and susceptible to treatment with endocrine therapy (especially with AIs).

The last limitation is that the women with AIs were slightly older than those without endocrine treatment ( $56.84 \pm 8.6$ vs. $54.93 \pm 0.42)$, although these differences were not statistically significant $(p=0.08$ ).

Despite these limitations, our study bridges psychology and cancer research for enhancing supportive cancer care. Finding the same proportion of mutilating surgery (radical mastectomy) in both groups increases the value of the results, since the effect of the surgery was not a bias on the impact of the QoL, possible sexual dysfunctions, or anxiety in the patients of our sample.

\section{Conclusions}

Given the relatively high rates of sexual dysfunction and sexual inactivity among postmenopausal BC survivors, especially AIs users (close to 50\% in our study), and the possibility that these rates are even higher but underestimated by both the patients themselves and the physician, we believe that the early detection of such dysfunctions through an appropriate clinical interview and/or the use of sexual function questionnaires could be useful to identify patients in need of behavioral (change of lifestyle), pharmacological, or even psychotherapeutic interventions.

Considering the higher anxiety levels of AI patients, they should be actively informed that sexual dysfunction, that has also a relevant social cost [31], will improve after
AI stopping and could be safely and effectively treated with nonhormonal treatments, like ospemifene [32]. While waiting, it is important to suggest trying to empower them telling that they can do something important even during AI use to keep up sexual activity. In order to do that, adequate moisturizer use can improve vaginal dryness, and pelvic floor exercises could maintain adequate vaginal blood flow and trophism, perineal muscular function, and ability to actively relax during intercourse [33].

\section{Acknowledgments}

The authors thank all the patients interviewed for participating in the study. We thank American Journal Experts for the language review.

\section{Statement of Ethics}

The study was conducted according to the guidelines of the Declaration of Helsinki and the National Health Council resolution 196/96 on research involving human subjects. Authorization was obtained from the Hospital Ethics Committee, and the informed consent of all patients involved in this study was obtained before data collection. This qualitative study was approved by the Medical Ethics Committee of the University Hospital of Puerto Real, Cádiz (Spain), in March 2016.

\section{Conflict of Interest Statement}

The authors did not report any potential conflicts of interest.

\section{Funding Sources}

This research did not receive any specific grant from funding agencies in the public, commercial, or not-for-profit sectors.

\section{Author Contributions}

The following contributions were made by the authors: D.M.L.L.: project conceptualization; D.M.L.L. and C.A.B.H.: data generation; D.M.L.L. and C.A.B.H. data analysis; D.M.L.L., N.M., and R.S.-B. clinical interpretation; D.M.L.L., N.M., and R.S.-B.: writing - original draft preparation; D.M.L.L., C.A.B.H., M.S.-P., N.M., and R.S.-B.: writing - review and editing. All authors have read and agreed to the published version of the manuscript.

\section{References}

1 Anderson WF, Chatterjee N, Ershler WB, Brawley OW. Estrogen receptor breast cancer phenotypes in the Surveillance, Epidemiology, and End Results database. Breast Cancer Res Treat. 2002 Nov;76(1):27-36.
2 Burstein HJ, Lacchetti C, Anderson H, Buchholz TA, Davidson NE, Gelmon KA, et al. Adjuvant endocrine therapy for women with hormone receptor-positive breast cancer: ASCO Clinical Practice Guideline Focused Update. J Clin Oncol. 2019 Feb;37(5):423-38.
3 Arraras JI, Illarramendi JJ, de la Cruz S, Asin G, Manterola A, Ibanez B, et al. Erratum: Quality of life in long-term premenopausal early-stage breast cancer survivors from Spain. Effects of surgery and time since surgery. J BUON. 2016 Nov-Dec;21(6):1573. 
4 Fiszer C, Dolbeault S, Sultan S, Brédart A. Prevalence, intensity, and predictors of the supportive care needs of women diagnosed with breast cancer: a systematic review. Psychooncology. 2014 Apr;23(4):361-74.

5 Hou WK, Lam JH. Resilience in the year after cancer diagnosis: a cross-lagged panel analysis of the reciprocity between psychological distress and well-being. J Behav Med. 2014 Jun;37(3):391-401.

6 Sánchez-Borrego R, Molero F, Castaño R, Castelo-Branco C, Honrado M, Jurado AR, et al. Spanish consensus on sexual health in men and women over 50. Maturitas. 2014 Jun; 78(2):138-45

7 Mendoza N, Carrión R, Mendoza-Huertas L, Jurado AR. Efficacy and Safety of Treatments to Improve Dyspareunia in Breast Cancer Survivors: A Systematic Review. Breast Care (Basel). 2020;1-9.

8 Sánchez-Borrego R, Mendoza N, Beltrán E, Comino R, Allué J, Castelo-Branco C, et al. Position of the Spanish Menopause Society regarding the management of menopausal symptoms in breast cancer patients. Maturitas. 2013 Jul;75(3):294-300.

9 Mok K, Juraskova I, Friedlander M. The impact of aromatase inhibitors on sexual functioning: current knowledge and future research directions. Breast. 2008 Oct;17(5): 436-40.

10 Gass JS, Onstad M, Pesek S, Rojas K, Fogarty S, Stuckey A, et al. Breast-Specific Sensuality and Sexual Function in Cancer Survivorship: Does Surgical Modality Matter? Ann Surg Oncol. 2017 Oct;24(11):3133-40.

11 Buijs C, de Vries EG, Mourits MJ, Willemse $\mathrm{PH}$. The influence of endocrine treatments for breast cancer on health-related quality of life. Cancer Treat Rev. 2008 Nov;34(7):64055.

12 Sprangers MA, Groenvold M, Arraras JI Franklin J, te Velde A, Muller M, et al. The European Organization for Research and Treatment of Cancer breast cancer-specific quality-of-life questionnaire module: first results from a three-country field study. J Clin Oncol. 1996 Oct;14(10):2756-68.

13 Vera R, Pruja E, Arraras JI, Tejedor M, Illarramendi JJ, Marcos M, et al. El cuestionario de calidad de vida para cáncer de mama de la EORTC, QLQ-BR23: estudio psicométrico con una muestra española. Psicol Conduct. 2001;9(1):81-98

14 Baser RE, Li Y, Carter J. Psychometric validation of the Female Sexual Function Index (FSFI) in cancer survivors. Cancer. 2012 Sep; 118(18):4606-18.

15 Pérez-Herrezuelo I, Hita-Contreras F, Martínez-Amat A, Aibar-Almazán A, Cruz-Díaz $\mathrm{D}$, Wangensteen $\mathrm{R}$, et al. The female sexual function index: reliability and validity in Spanish postmenopausal women. Menopause. 2019 Apr;26(4):401-8.

16 Spielberger CD, Gorsuch RL, Lushene RE. Cuestionario de ansiedad estado-rasgo. Adaptación española de Seisdedos N. 7th ed. Madrid: TEA Ediciones SA; 2008.

17 Buela-Casal G, Guillén-Riquelme A. Short form of the Spanish adaptation of the StateTrait Anxiety Inventory. Int J Clin Health Psychol. 2017 Sep-Dec;17(3):261-8.

18 Lindau ST, Abramsohn EM, Matthews AC. A manifesto on the preservation of sexual function in women and girls with cancer. Am J Obstet Gynecol. 2015 Aug;213(2):166-74

19 Sadovsky R, Basson R, Krychman M, Morales AM, Schover L, Wang R, et al. Cancer and sexual problems. J Sex Med. 2010 Jan;7(1 Pt 2):349-73.

20 de Morais FD, Freitas-Junior R, Rahal RM, Gonzaga CM. Sociodemographic and clinical factors affecting body image, sexual function and sexual satisfaction in women with breast cancer. J Clin Nurs. 2016 Jun;25(11-12): 1557-65.

21 Zhang JY, Zhou YQ, Feng ZW, Fan YN, Zeng GC, Wei L. Randomized controlled trial of mindfulness-based stress reduction (MBSR) on posttraumatic growth of Chinese breast cancer survivors. Psychol Health Med. 2017 Jan;22(1):94-109.

22 Schover LR, Baum GP, Fuson LA, Brewster A, Melhem-Bertrandt A. Sexual problems during the first 2 years of adjuvant treatment with aromatase inhibitors. J Sex Med. 2014 Dec; 11(12):3102-11.

23 Sánchez-Borrego R. Sex after breast and gynecological cancer. Maturitas. 2015;81(1): 106-7.
24 Hopkins TG, Stavraka C, Gabra H, Fallowfield L, Hood C, Blagden S. Sexual activity and functioning in ovarian cancer survivors: an internet-based evaluation. Climacteric. 2015 Feb;18(1):94-8.

25 Baumgart J, Nilsson K, Evers AS, Kallak TK, Poromaa IS. Sexual dysfunction in women on adjuvant endocrine therapy after breast cancer. Menopause. 2013 Feb;20(2):162-8

26 Gandhi C, Butler E, Pesek S, Kwait R, Edmonson D, Raker C, et al. Sexual Dysfunction in Breast Cancer Survivors: Is it Surgical Modality or Adjuvant Therapy? Am J Clin Oncol. 2019 Jun;42(6):500-6.

27 Sussman TA, Kruse ML, Thacker HL, Abraham J. Managing Genitourinary Syndrome of Menopause in Breast Cancer Survivors Receiving Endocrine Therapy. J Oncol Pract. 2019 Jul;15(7):363-70.

28 Kingsberg SA, Larkin L, Krychman M, Parish SJ, Bernick B, Mirkin S. WISDOM survey: attitudes and behaviors of physicians toward vulvar and vaginal atrophy (VVA) treatment in women including those with breast cancer history. Menopause. 2019 Feb;26(2):124-31.

29 Crean-Tate KK, Faubion SS, Pederson HJ, Vencill JA, Batur P. Management of genitourinary syndrome of menopause in female cancer patients: a focus on vaginal hormonal therapy. Am J Obstet Gynecol. 2020 Feb 222(2):103-13

30 Palacios S, Panay N, Sánchez-Borrego R, Particco M, Djumaeva S. Earlier Treatment of Vulvovaginal Atrophy in Post-Menopausal Women May Improve Treatment Outcomes. J Gynecol Women's Health. 2019;16:555928.

31 Biglia N, Del Pup L, Masetti R, Villa P, Nappi RE. Vulvovaginal atrophy (VVA) in breast cancer survivors (BCS) is still an unmet medical need: results of an Italian Delphi Panel. Support Care Cancer. 2020 Jun;28(6):2507-12.

32 Pup LD, Sánchez-Borrego R. Ospemifene efficacy and safety data in women with vulvovaginal atrophy [published online ahead of print, 2020 Apr 24]. Gynecol Endocrinol. 2020 Jul;36(7):569-77.

33 Del Pup L, Villa P, Amar ID, Bottoni C, Scambia G. Approach to sexual dysfunction in women with cancer. Int J Gynecol Cancer. 2019 Mar;29(3):630-4. 